\title{
Response of recurrent BRAFV600E mutated ganglioglioma to Vemurafenib as single agent
}

\author{
Francesca del Bufalo ${ }^{1}$, Andrea Carai ${ }^{2}$, Lorenzo Fig-Talamanca ${ }^{3}$, Benedetta Pettorini ${ }^{4}$, Conor Mallucci ${ }^{4}$, \\ Felice Giangaspero ${ }^{5,6}$, Manila Antonelli ${ }^{5}$, Manuela Badiali' ${ }^{7}$ Loredana Moi ${ }^{8}$, Giuseppe Bianco ${ }^{9}$, Antonella Cacchione ${ }^{1}$, \\ Franco Locatelli ${ }^{1,10}$, Elisabetta Ferretti ${ }^{1{ }^{*}}$ and Angela Mastronuzzi ${ }^{1}$
}

\begin{abstract}
Background: Ganglioglioma (GG) and pilocytic astrocytoma (PA) represent the most frequent low-grade gliomas (LGG) occurring in paediatric age. LGGs not amenable of complete resection (CR) represent a challenging subgroup where traditional treatments often fail. Activation of the MAP Kinase (MAPK) pathway caused by the BRAFV600E mutation or the KIAA1549-BRAF fusion has been reported in pediatric GG and PA, respectively.

Case presentation: We report on a case of BRAFV600E mutated cervicomedullary GG treated with standard chemotherapy and surgery. After multiple relapse, BRAF status was analyzed by immunohistochemistry and sequencing showing a BRAFV600E mutation. Treatment with Vemurafenib as single agent was started. For the first time, a radiological and clinical response was obtained after 3 months of treatment and sustained after 6 months.

Conclusion: Our experience underline the importance of understanding the driver molecular alterations of LGG and suggests a role for Vemurafenib in the treatment of pediatric GG not amenable of complete surgical resection.
\end{abstract}

Keywords: Low Grade Glioma, Ganglioglioma, MAP Kinase pathway, BRAF V600E, Vemurafenib

\section{Background}

Ganglioglioma (GG) and pilocytic astrocytoma (PA) represent the most frequent low-grade gliomas (LGG) occurring in paediatric age. When complete resection (CR) is obtained, the prognosis of these tumours is excellent. If $\mathrm{CR}$ is not safely achievable, the management can be extremely challenging and often ineffective despite chemo and/or radiotherapy, leading to a worse prognosis.

Activation of the MAP Kinase (MAPK) pathway has been shown to be the main molecular alteration present in LGG and can be caused by duplication or mutation of the BRAF gene [1]. In PA the most frequent genetic alteration consists in a duplication of the $7 \mathrm{q} 34$ region leading to a KIAA1549-BRAF fusion protein that is constitutively active whereas in GG the BRAFV600E mutation is more frequent. Inhibitors of MAPK pathway have been considered as a potential target therapy for these tumours [2,3]. Among such inhibitors Vemurafenib, a

\footnotetext{
* Correspondence: elisabetta.ferretti@uniroma1.it

${ }^{11}$ Department of Experimental Medicine, Sapienza University, Viale Regina Elena 291, 00161 Rome, Italy

Full list of author information is available at the end of the article
}

competitive small molecule that selectively recognizes the ATP binding domain of the BRAFV600E mutant, has proved effective in the treatment of metastatic melanoma, a neoplasm frequently mutated for BRAF. More recently, an activity of this drug was proved also in pediatric BRAFV600E mutated malignant astrocytomas [4-6].

Herein, we report on a case of BRAFV600E mutated cervicomedullary LGG successfully treated with Vemurafenib as single agent after failure of conventional treatment.

\section{Case report}

A 28-month-old boy was transferred to our emergency department from a local hospital in assisted ventilation for a respiratory insufficiency in June 2009. MRI performed during diagnostic work up revealed a bulky mass with cystic component extending from medulla into cervical spinal cord to $\mathrm{C} 5$ and dislocating the pons, the floor of the IV ventricle, the cerebellar vermis and tonsils (Figure 1A). As gross total resection (GTR) was not considered feasible, surgical decompression and a biopsy of the exophitic portion of the lesion were performed revealing a LGG with features compatible with PA. 

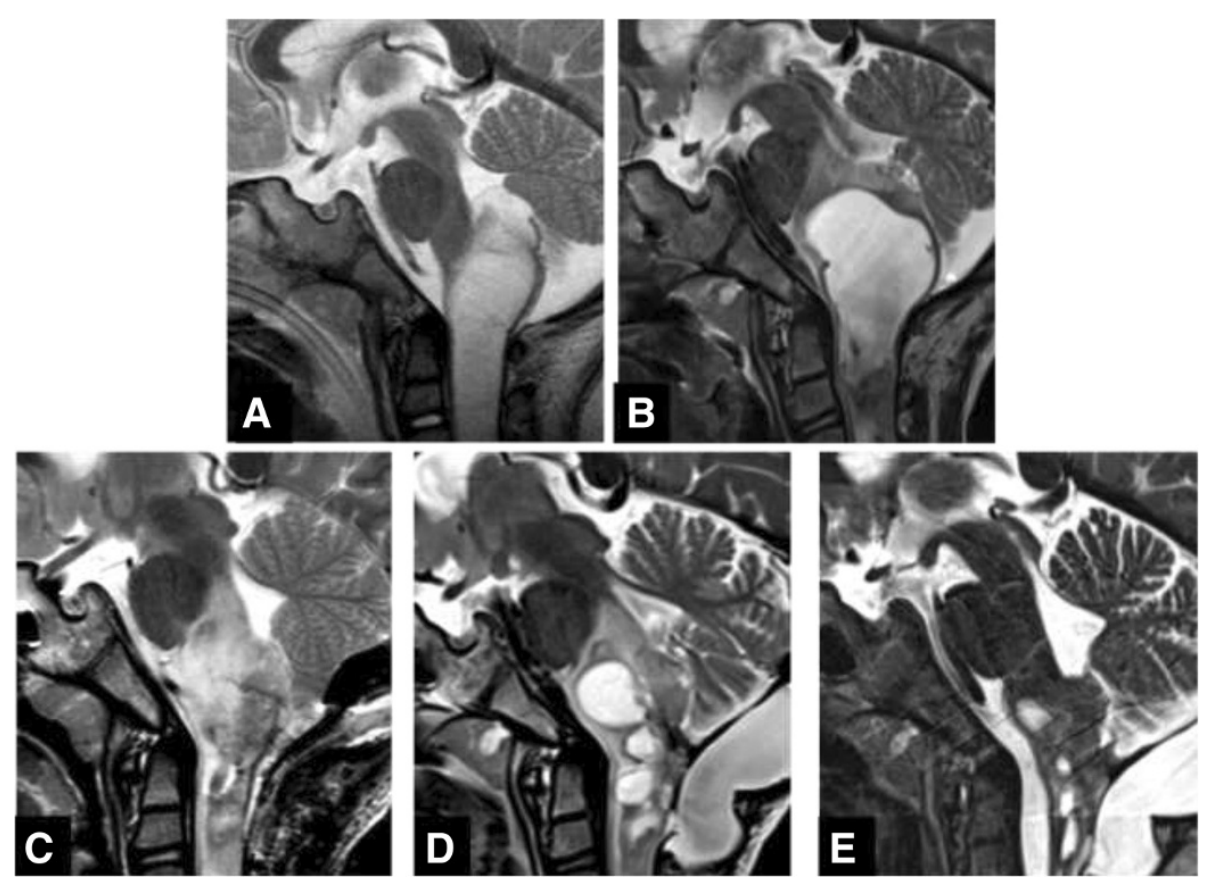

Figure 1 Serial MRI features of the lesion. Sagittal T2 weighted images show, at onset, a bulky mass extending from medulla into cervical spinal cord, dislocating the pons, the floor of the IV ventricle, the cerebellar vermis and tonsils (A); increased size of both cystic and solid component of the lesion after surgical decompression and chemotherapy (B); a new disease progression three months after second surgery (C); further increase of cystic components (D); a relevant reduction in size of both the solid and the cystic components of the lesion six months after the start of treatment $\mathbf{( E )}$.

Polysomnographic exam revealed a relevant number of episodes of oxygen desaturation $>4 \%$ of central origin. Tracheotomy was performed and chemotherapy according to the SIOP LGG 2004 protocol started. Unfortunately, the tumour did not respond to treatment showing a gradual clinical and radiological progression with worsening of the nocturnal episodes of desaturation and progressive increase of size of both a cystic portion of the lesion and the solid component (Figure 1B). A second surgery was performed in 2012 in order to reduce the cystic component of the lesion. The histological examination of the residual lesion showed the presence, in addition to the glial component, of mature ganglion cells, leading to a diagnosis of ganglioglioma (GG) (Figure 2) with classical morphology, i.e. neoplastic astrocytes and ganglion cells with dysplastic, binucleated neuron, embedded in tissue with eosinhophilic granular body and lymphocytic intratumoral infiltrate. MRI 3 months after surgery revealed a new disease progression with evidence of multicystic component in the brainstem and cervical spine, which appeared to be related to syringobulbia and syringomyelia secondary to cerebrospinal fluid outflow impairment

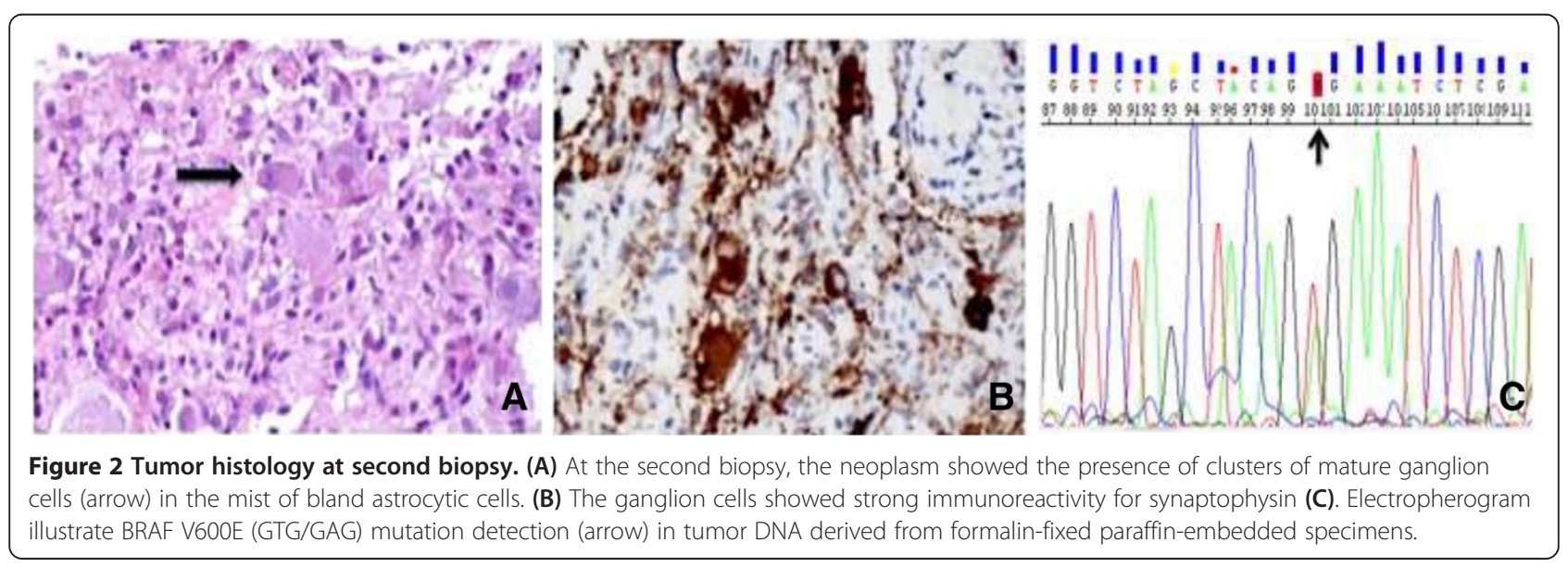


(Figure 1C). In order to improve local control of the cystic component, a new attempt of debulking was performed; intraoperative brainstem monitoring showed functional responses in the context of the solid component of the tumour and further resection was then abandoned. Two syringe-subarachnoid stents were then inserted to achieve decompression of the cysts. Unfortunately, after an initial stabilization, slow clinical and radiological progression were documented (Figure 1D) and the child began to experience swallowing difficulties and worsening of nocturnal oxygen desaturations. Radiotherapy was not advised due to patients age and proton beam therapy was not deemed feasible due to extension of disease in a critical location.

Considering the progressive clinical deterioration of the patient and the absence of other effective options, molecular testing for evaluation of a target therapy was performed on the tumour tissue from the first biopsy: according to data from the literature, the KIAA-BRAF fusion gene detection and BRAFV600E testing were performed on fresh frozen (FF) tumor tissue by RT-PCR, PCR amplification and subsequent sequencing.

DNA was extracted from FF tissue specimen using the QIAamp DNA Mini Kit, as described by the manufacturer (Qiagen S.A., Courtaboeuf France). Total RNA was extracted from FF tissue using Eurogold Trifast (by Euroclone). DNA and RNA concentrations were quantified using the Nanodrop ND-1000 UV vis spectrophotometer (Labtech France, Palaiseau, France) and the integrity of nucleic acid was determinated using Quanti-it RNA Assay kit and quanti-dsDNA BR assay kit with Quibit fluorometer (by Invitrogen- Life Technologies). Final products were stored at $-20 \mathrm{C}$ until use.

Moreover standard diagnostic procedure were performed. Sections were stained with ematoxilin and eosin, and immunohistochemical stain for synaptophysin (Mouse Monoclonal Antibody Synaptophysin diluition 1:200, Novocastra Clone 27G12), was performed on paraffin section using labelled strepavidin-biotin peroxidise technique. Antigen retrieval was effected by pressure cooking in citrate buffer pH6. The sections was counterstained with hematoxilin.

\section{KIAA1549:BRAF fusion-gene by sequencing}

Reverse-transcription polymerase chain reaction (RT-PCR) was performed on $1 \mu \mathrm{g}$ of total RNA using High Capacity cDNA Reverse Transcriptionkit (Life Technologies) according to the manufacturers protocol. The integrity of the resulting cDNA was checked by amplifying the wild-type locus of the BRAF gene (in exon $6 / 7$ ) and then submitted to PCR with specific pairs of primers flanking the fusion point between the KIAA1549 (in exon 15 or 16) and BRAF (in exon 9 or 11) genes as described by Jones et al. [7]. The purified PCR products were then sequenced using the
BigDye Terminator v1.1 Cycle Sequencing Kit (Applied Biosystems, Courtaboeuf, France) with the forward and reverse primer used to perform the PCR. Sequencing was performed using the ABI 3130 XL DNA analyser (Applied Biosystem). The sequences of primers used were as follows: KIAA1549 exon 15: 5'-CGG AAA CAC CAG GTC AAC GG-3'; KIAA1549 exon 16: 5'-AAA CAG CAC CCC TTC CCA GG-3'; BRAF exon 9: 5' -CTC CAT CAC CAC GAA ATC CTT G-3'; BRAF exon 11: 5' -GTT CCA AAT GAT CCA GAT CCA TTC-3'. RT-PCR from RNA didn $t$ show the presence of the KIAA1549-BRAF fusion gene (data not shown).

\section{BRAFV600E mutation analysis}

Mutational analysis was performed amplifying DNA with the primers as follows: BRAF exon 15, $5^{\prime}$ - TCA TAA TGC TTG CTC TGA TAG GA-3' (sense) and 5'-GGC CAA AAA TTT AAT CAG TGG A-3' (antisense). The PCR products were purified using the automated system Biomek NXp by Beckman Coulter and Agentcourt AMPure XP reagents. Purified products were submitted to PCR cycle sequencing conditions as follow: denaturation at $95 \mathrm{C}$ for $30 \mathrm{~s}$, annealing at $50 \mathrm{C}$ for $15 \mathrm{~s}$, and extention at $60 \mathrm{C}$ for $240 \mathrm{~s}$. The cycle sequencing products were purified using the same automated system and Agentcourt Clean SEQ reagents. Sequencing analysis was performed using the ABI 3130 XL DNA analyser (Applied Biosystem). DNA analysis sequencing revealed BRAFV600E mutation (Figure 2C).

Based on these results, a treatment with Vemurafenib was started on compassionate use in November 2013 (240 mg, $370 \mathrm{mg} / \mathrm{m}^{2}$, twice a day (BID), equivalent to the minimal dose that proved active in the adult cohort). The therapy was overall well tolerated: accurate dermatological and ECG monitoring were performed and no ECG changes nor skin lesions were observed. The only side effect reported was a transient grade 3 Common Toxicity Criteria (version 4) skin rash that resolved spontaneously. MRI performed 3 months after the start of treatment revealed, for the first time, a reduction in size of both the solid and the cystic components of the disease, a trend confirmed after 6 months of treatment (Figure 1E). Accordingly, clinical symptoms improved with complete restoration of the swallowing function and reduction of the nocturnal episodes of desaturation.

\section{Discussion}

Gangliogliomas are rare, well-differentiated, neuroepithelial tumors that most commonly affect children and young adults. They occur more commonly in the supratentorial region, mostly in the temporal lobe (up to $85 \%$ ), but can occasionally develop also in the brainstem, cerebellopontine angle, thalamus, optic nerve and spinal cord. Included in the broad category of LGG, they are 
considered indolent tumors with excellent long-term survival [8].

Surgery is generally recognized as the treatment of choice for GGs, aimed at achieving a safe complete tumour resection [9]. Accordingly, the location of the tumour has also an impact on the PFS, influencing the management of the disease and the possibility of achieving a radical surgery [10]. On these bases, LGGs occurring along the midline (chiasma/hypothalamus, basal ganglia and brainstem) display a poorer outcome as compared to tumours in other locations, with a higher risk of disease progression and an indolent course, resulting in a high OS [11]. The role of chemotherapy in the treatment of LGG is still debated: several approaches have been evaluated showing variable response rates with substantially low 5-years PSF [12]. Despite these results, to date it represents the only available approach to delay RT in younger children with unresectable LGG.

Radiotherapy (RT) is considered the treatment of choice for LGG not amenable of surgical resection, therefore representing the best option for centrally located tumours $[13,14]$. Unfortunately, adverse effects preclude its use in younger children (until at least 5 , possibly 8 years of age), leading to a substantial increase in the risk of progression for this category of patients. Moreover, even when used in older children, long term vasculopathy, hearing loss and neurocognitive and endocrinological sequelae remain a relevant concern [15]. Therefore, taking into consideration the natural history of tumour stabilization, its indolent course and the high likelihood of long-term survival, the use of RT must be carefully weighed.

Our child presented with a rare cervicomedullary GG. Although the histology resulted favorable, the location and the age of the child represented relevant negative prognostic factors, preventing complete surgical removal of the lesion and the use of RT. In order to obtain a stabilization of the disease, standard chemotherapy based on SIOP LGG 2004 protocol was administered. Unfortunately, but not surprisingly, the child clinically and radiologically progressed at the end of the treatment, confirming the indolent but progressive course of this disease.

The recent finding of driver genomic alterations in BRAF gene in LGG and the development of new molecules that interfere with this deregulated signaling are highly attractive, especially in patients with midline, unresectable tumours, and when RT is not recommended, in order to overcome treatment limitations and improve cure rate.

In 2008, different groups identified gains at $7 \mathrm{q} 34$ of approximately 2 megabases in size in most LGG, representing segmental duplications of the region [1,2,16-18]. This duplication leads to the formation of a fusion between the KIAA1549 locus and BRAF and the resulting protein displays a constitutively activated kinase activity causing an aberrant activation of the downstream MAPK/ ERK pathway. Subsequent studies revealed other, less common, molecular alterations in BRAF gene driving activation of the same pathway $[3,19,20]$ : the most frequent is the point mutation that occurs at codon 600 (BRAFV600E), firstly associated with several non-CNS human tumors, that results in substitution of valine by glutamic acid [21,22].

BRAFV600E mutation appears to be particularly associated with paediatric GG where its status changes based on the anatomical location. Although Schindler et al. could not identify it, the mutation seems to be present in a relatively high percentage of cases with brainstem location [3,23-25].

The prognostic relevance of BRAF duplication/mutation is not clear yet: some reports suggest an association with a better outcome in children displaying BRAF fusion and a trend toward a lower PFS in LGG expressing BRAFV600E mutation while other groups could not confirm these findings [26-30]. Dahiya et al. revealed a significantly worse recurrence-free survival of BRAFV600E-mutated GG compared to negative tumors, suggesting a negative prognostic role for this mutation in GG [8].

Novel therapies targeting the altered BRAF pathway have been developed, including the oral drug Vemurafenib. After showing impressive, although transient, results on recurrent melanoma, it has been approved by the FDA for the treatment of unresectable or metastatic melanoma. The drug proved well tolerated so far in adults, with arthralgia, rash, alopecia, fatigue, photosensitivity reaction, nausea, pruritus and skin lesions reported as main toxicities [31]. Overall, a variety of skin toxicities has been reported and therefore a careful examination is recommended during treatment [32].

The use of an oral target therapy to control the disease in children with unresectable LGG is highly suitable. In vitro and in vivo studies of paediatric astrocytoma cell lines expressing BRAFV600E mutation have been performed and show that target inhibition of mutated BRAF exerts an antiproliferative activity and slows tumour growth, improving survival [4]. With this strong supportive rationale, a safety and pilot efficacy clinical trial of Vemurafenib against BRAFV600E mutant recurrent or refractory LGG in children has recently started (ClinicalTrials.gov Identifier: NCT01748149). To the best of our knowledge, only one report on the use of this drug in pediatric low grade GG has been published and showed encouraging results, in association with vinorelbine [33].

Taking into consideration all these evidences and the persistent progression of our patient, we decided to evaluate the presence of BRAFV600E mutation in order to initiate treatment with Vemurafenib. Since no pharmacokinetic data nor toxicity analysis are available in the 
pediatric population to date, we decided to start the treatment with the minimal dose that proved active in the adult cohort, and maintained it in consideration of the results shown [34]. The excellent, rapid and sustained response documented in our child after 6 months of treatment shows a relevant efficacy of this small-molecule inhibitor in a challenging subcategory of LGG, although a longer follow-up is required to define the long-term response to this drug. Notably, our patient did not receive any other concurrent chemotherapy, proving that the observed response can be attributed exclusively to the BRAF inhibitor.

The lesson provided by the use of Vemurafenib in melanoma patients, however, warns treatment [35]. Moreover, in the context of malignant GG, few reports have proved a not uniform activity of Vemurafenib [6]. Although not clear yet, these diverse responses are likely related to the complex genetic aberrations present in malignant gliomas which might induce the overactivation of MAP kinase through alternative pathways, regardless of the BRAF status, and thus impair the efficacy of the treatment. Similarly, the mechanisms underlying the acquired resistance are multiple and not fully understood yet. Most of them rely upon the alternative reactivation of the MAP kinase signaling pathway through the mutational activation of other key molecule of the pathway, such as NRAS, MEK1 or MEK2, or the occurrence of BRAF-V600E splice variants [36-38]. Moreover, MAPK pathway-independent mechanisms of resistance have been also suggested, involving alterations that lead to the upregulation of the PI3K-AKT signaling pathway [39]. Therefore, the combination with either MEK, ERK or PI3K inhibitors might be considered to overcome both intrinsic and acquired resistance.

The optimal tolerance to the treatment and the advantage of the oral administration represent relevant aspects in the context of LGG as they reduce the burden of the frequent hospitalization that these children and their families face, sometimes for several years. It is important to point out, however, that the induction of secondary cutaneous lesions and the promotion of proliferation of pre-malignant cells harboring RAS mutation in noncutaneous tissues, reported in some adult patients, raise considerable concern, especially in the pediatric population. Therefore, a careful case-specific consideration of the risk/benefit ratio is mandatory until more detailed documentation will be provided by clinical trials.

\section{Conclusions}

To our knowledge, this is the first case describing the use of Vemurafenib as single agent in paediatric GG. Our experience, although limited to a case report, and the review of the literature underline the importance of understanding the driver molecular alterations of LGG to improve treatment strategies, through target therapies, and ultimately outcome of these patients. As specific BRAF inhibitors are now available, the evaluation of BRAF status in children with tumors not amenable of GTR should be considered in order to offer a valuable therapeutic alternative. A wider molecular signature, moreover, might be required in case of low response or relapse, in order to further improve the activity by multiple targeting. Large clinical trials are needed to further evaluate the pharmacokinetic profile, safety and efficacy of BRAF inhibitor in the treatment of LGG with this signature and the time of suspension of this therapy, considering the possibility of relapse/progression of disease at the end of treatment.

\section{Consent}

Written informed consent was obtained from the patients parent for the publication of this report and any accompanying images.

\section{Competing interests}

The authors declare that they have no competing interests.

\section{Authors contributions}

FdB contributed to treat the patient and wrote the article; AC performed surgery and wrote the article; BP and CM, performed surgery and followed the patient; LFT performed MRI studies; FG supervised histological and molecular studies and interpreted data; MA, MB and LM performed histological and molecular analysis; GB and AC provided the treatment and contributed to the writing; FL and EF have critically reviewed the manuscript; AM treated the patient, interpreted data and wrote the article. All authors read and approved the final manuscript.

\section{Acknowledgements}

The authors would like to thank patient s family for collaboration.

\section{Source of fundings}

No funding was secured for this study.

\section{Author details}

'Department of Hematology/Oncology and Stem Cell Transplantation, Bambino Ges Children s Hospital, IRCCS, Piazza Sant Onofrio 4, 00165 Rome, Italy. ${ }^{2}$ Department of Neuroscience and Neurorehabilitation, Neurosurgery Unit, Bambino Ges Children s Hospital, IRCCS, Piazza Sant Onofrio 4, 00165 Rome, Italy. ${ }^{3}$ Department of Radiology, Unit of Neuroradiology, Bambino Ges Children s Hospital, IRCCS, Piazza Sant Onofrio 4, 00165 Rome, Italy. ${ }^{4}$ Paediatric Neurosurgery Department, Alder Hey Children s NHS Foundation Trust, Liverpool, UK. ${ }^{5}$ Department of Radiological, Oncological and Pathological Science, Sapienza University, Viale Regina Elena 291, 00161 Rome, Italy. ${ }^{6}$ Neuromed Institute, IRCCS, Via Atinense 18, 86077 Isernia, Pozzilli, IS, Italy. ${ }^{7}$ Bone Marrow Transplantation Unit, Microcitemico Children s Hospital, Via Jenner s/n 09121, Cagliari, Italy. ${ }^{8}$ Public Health, Clinic and Molecular Medicine Department, Microcitemico Children s Hospital, Via Jenner s/n 09121, Cagliari, Italy. ${ }^{9}$ Pharmacy Unit, Bambino Ges Children s Hospital, IRCCS, Piazza Sant Onofrio 4, 00165 Rome, Italy. ${ }^{10}$ University of Pavia, Strada Nuova, 27100 Pavia, Italy. ${ }^{11}$ Department of Experimental Medicine, Sapienza University, Viale Regina Elena 291, 00161 Rome, Italy.

Received: 27 August 2014 Accepted: 4 December 2014

Published online: 19 December 2014

\section{References}

1. Pfister S, Janzarik WG, Remke M, Ernst A, Werft W, Becker N, Toedt G, Wittmann A, Kratz C, Olbrich H, Ahmadi R, Thieme B, Joos S, Radlwimmer B, Kulozik A, Pietsch T, Herold-Mende C, Gnekow A, Reifenberger G, Korshunov A, Scheurlen W, Omran H, Lichter P: BRAF gene duplication constitutes a mechanism of MAPK pathway activation in low-grade astrocytomas. J Clin Invest 2008, 118:1739 1749 
2. Jacob K, Albrecht S, Sollier C, Faury D, Sader E, Montpetit A, Serre D, Hauser P, Garami M, Bognar L, Hanzely Z, Montes JL, Atkinson J, Farmer JP, Bouffet E, Hawkins C, Tabori U, Jabado N: Duplication of 7q34 is specific to juvenile pilocytic astrocytomas and a hallmark of cerebellar and optic pathway tumours. Br J Cancer 2009, 101:722 733.

3. Schindler G, Capper D, Meyer J, Janzarik W, Omran H, Herold-Mende C, Schmieder K, Wesseling P, Mawrin C, Hasselblatt M, Louis DN, Korshunov A Pfister S, Hartmann C, Paulus W, Reifenberger G, von Deimling A: Analysis of BRAFV600E mutation in 1,320 nervous system tumors reveals high mutation frequencies in pleomorphic xanthoastrocytoma, ganglioglioma and extra-cerebellar pilocytic astrocytoma. Acta Neuropathol 2011, 121:397 405.

4. Nicolaides TP, Li H, Solomon DA, Hariono S, Hashizume R, Barkovich K, Baker SJ, Paugh BS, Jones C, Forshew T, Hindley GF, Hodgson JG, Kim JS, Rowitch DH, Weiss WA, Waldman TA, James CD: Targeted therapy for BRAFV600E malignant astrocytoma. Clin Cancer Res 2011, 17:7595 7604.

5. Robinson GW, Brent AO, Gajjar A: Complete clinical regression of a BRAF V600E-mutant pediatric glioblastoma multiforme after BRAF inhibitor therapy. BMC Cancer 2014, 14:258.

6. Bautista F, Paci A, Minard-Colin V, Dufour C, Grill J, Lacroix L, Varlet P, ValteauCouanet D, Georerger B: Vemurafenib in pediatric patients with BRAFV600E mutated high grade gliomas. Pediat Blood Cancer 2014, 61:1101 1103.

7. Jones DT, Kocialkowski S, Liu L, Pearson DM, Backlund LM, Ichimura K, Collins VP. Tandem duplication producing a novel oncogenic BRAF fusion gene defines the majority of pilocytic astrocytomas. Cancer Res 2008, 68:8673 8677.

8. Dahiya S, Haydon DH, Alvarado D, Gurnett CA, Gutmann DH, Leonard JR: BRAF(V600E) mutation is a negative prognosticator in pediatric ganglioglioma. Acta Neuropathol 2013, 125:901 910.

9. Walker DA, Liu J, Kieran M, Jabado N, Picton S, Packer R, St Rose C, CPN Paris 2011 Conference Consensus Group: A multi-disciplinary consensus statement concerning surgical approaches to low-grade, high-grade astrocytomas and diffuse intrinsic pontine gliomas in childhood (CPN Paris 2011) using the Delphi method. Neuro Oncol 2013, 15:462 468.

10. Stokland T, Liu JF, Ironside JW, Ellison DW, Taylor R, Robinson KJ, Picton SV, Walker DA: A multivariate analysis of factors determining tumor progression in childhood low-grade glioma: a population-based cohort study (CCLG CNS9702). Neuro Oncol 2010, 12:1257 1268.

11. Terashima K, Chow K, Jones J, Ahern C, Jo E, Ellezam B, Paulino AC, Okcu MF, Su J, Adesina A, Mahajan A, Dauser R, Whitehead W, Lau C, Chintagumpala M: Long-term outcome of centrally located low-grade glioma in children. Cancer 2013, 119:2630 2638.

12. Ater JL, Zhou T, Holmes E, Mazewski CM, Booth TN, Freyer DR, Lazarus KH, Packer RJ, Prados M, Sposto R, Vezina G, Wisoff JH, Pollack IF: Randomized study of two chemotherapy regimens for treatment of low-grade glioma in young children: a report from the Childrens Oncology Group. J Clin Oncol 2012, 30:2641 2647.

13. Packer RJ: Radiation Therapy for Pediatric Low-Grade Gliomas: Survival and Sequelae. Curr Neurol Neurosci Rep 2010, 10:10 13.

14. Merchant TE, Kun LE, Wu S, Xiong X, Sanford RA, Boop FA: Phase II trial of conformal radiation therapy for pediatric low-grade gliomas. J Clin Oncol 2009, 27:3598 3604.

15. Merchant TE, Conklin HM, Wu S, Lustig RH, Xiong X: Late effects of conformal radiation therapy for pediatric patients with low grade glioma: prospective evaluation of cognitive, endocrine, and hearing deficits. J Clin Oncol 2009, 27:3691 3697.

16. Deshmukh H, Yeh TH, Yu J, Sharma MK, Perry A, Leonard JR, Watson MA, Gutmann DH, Nagarajan R: High-resolution, dual-platform aCGH analysis reveals frequent HIPK2 amplification and increased expression in pilocytic astrocytomas. Oncogene 2008, 27:4745 4751

17. Bar EE, Lin A, Tihan T, Burger PC, Eberhart CG: Frequent gains at chromosome 7q34 involving BRAF in pilocytic astrocytoma. J Neuropathol Exp Neurol 2008, 67:878 887.

18. Sievert AJ, Jackson EM, Gai X, Hakonarson H, Judkins AR, Resnick AC, Sutton LN, Storm PB, Shaikh TH, Biegel JA: Duplication of 7q34 in pediatric low-grade astrocytomas detected by high density single-nucleotide polymorphism-based genotype arrays results in a novel BRAF fusion gene. Brain Pathol 2009, 19:449 458.

19. Janzarik WG, Kratz CP, Loges NT, Olbrich H, Klein C, Schafer T, Scheurlen W Roggendorf W, Weiller C, Niemeyer C, Korinthenberg R, Pfister S, Omran H: Further evidence for a somatic KRAS mutation in a pilocytic astrocytoma. Neuropediatrics 2007, 38:61 63
20. Marko NF, Weil RJ: The molecular biology of WHO grade I astrocytomas. Neuro Oncol 2012, 14:1424 1431.

21. Davies H, Bignell GR, Cox C, Stephens P, Edkins S, Clegg S, Teague J, Woffendin H, Garnett MJ, Bottomley W, Davis N, Dicks E, Ewing R, Floyd Y, Gray K, Hall S, Hawes R, Hughes J, Kosmidou V, Menzies A, Mould C, Parker A, Stevens C, Watt S, Hooper S, Wilson R, Jayatilake H, Gusterson BA, Cooper C, Shipley J, Hargrave D, Pritchard-Jones K, Maitland N, Chenevix-Trench G, Riggins GJ, Bigner DD, Palmieri G, Cossu A, Flanagan A, Nicholson A, Ho JW, Leung SY, Yuen ST, Weber BL, Seigler HF, Darrow TL, Paterson H, Marais R, Marshall CJ, Wooster R, Stratton MR, Futreal PA: Mutations of the BRAF gene in human cancer. Nature 2002, 417:949 954.

22. Zhang J, Wu G, Miller CP, Tatevossian RG, Dalton JD, Tang B, Orisme W, Punchihewa C, Parker M, Qaddoumi I, Boop FA, Lu C, Kandoth C, Ding L, Lee R, Huether R, Chen X, Hedlund E, Nagahawatte P, Rusch M, Boggs K, Cheng J, Becksfort J, Ma J, Song G, Li Y, Wei L, Wang J, Shurtleff S, Easton J, Zhao D, Fulton RS, Fulton LL, Dooling DJ, Vadodaria B, Mulder HL, Tang C, Ochoa K, Mullighan CG, Gajjar A, Kriwacki R, Sheer D, Gilbertson RJ, Mardis ER, Wilson RK, Downing JR, Baker SJ, Ellison DW: St. Jude Children s Research Hospital Washington University Pediatric Cancer Genome Project..Whole-genome sequencing identifies genetic alterations in pediatric low-grade gliomas. Nat Genet 2013, 45:602 612.

23. Chapp C, Padovani L, Scavarda D, Forest F, Nanni-Metellus I, Loundou A, Mercurio S, Fina F, Lena G, Colin C, Figarella-Branger D: Dysembryoplastic neuroepithelial tumors share with pleomorphic xanthoastrocytomas and gangliogliomas BRAF mutation and expression. Brain Pathol 2013, 23:574 583 .

24. Koelsche C, Whrer A, Jeibmann A, Schittenhelm J, Schindler G, Preusser M, Lasitschka F, von Deimling A, Capper D: Mutant BRAFV600E protein in ganglioglioma is predominantly expressed by neuronal tumor cells. Acta Neuropathol 2013, 125:891900.

25. Donson AM, Kleinschmidt-DeMasters BK, Aisner DL, Bemis LT, Birks DK, Levy JM, Smith AA, Handler MH, Foreman NK, Rush SZ: Pediatric Brainstem Gangliogliomas Show BRAF(V600E) Mutation in a High Percentage of Cases. Brain Pathol 2014, 24:173 183.

26. Horbinski C, Nikiforova MN, Hagenkord JM, Hamilton RL, Pollack IF: Interplay among BRAF, p16, p53, and MIB1 in pediatric low-grade gliomas. Neuro Oncol 2012, 14:777 789.

27. Hawkins C, Walker E, Mohamed N, Zhang C, Jacob K, Shirinian M, Alon N, Kahn D, Fried I, Scheinemann K, Tsangaris E, Dirks P, Tressler R, Bouffet E, Jabado N, Tabori U: BRAFKIAA1549 fusion predicts better clinical outcome in pediatric low-grade astrocytoma. Clin Cancer Res 2011 17:4790 4798

28. Jeuken JW, Wesseling P: MAPK pathway activation through BRAF gene fusion in pilocytic astrocytomas; a novel oncogenic fusion gene with diagnostic, prognostic, and therapeutic potential. J Pathol 2010, 222:324 328.

29. Cin H, Meyer C, Herr R, Janzarik WG, Lambert S, Jones DT, Jacob K, Benner A, Witt $H$, Remke M, Bender S, Falkenstein F, Van Anh TN, Olbrich $H$, von Deimling A, Pekrun A, Kulozik AE, Gnekow A, Scheurlen W, Witt O, Omran H, Jabado N, Collins VP, Brummer T, Marschalek R, Lichter P, Korshunov A, Pfister SM: Oncogenic FAM131B-BRAF fusion resulting from 7q34deletion comprises an alternative mechanism of MAPK pathway activation in pilocytic astrocytoma. Acta Neuropathol 2011, 121:763 774

30. Lin A, Rodriguez FJ, Karajannis MA, Williams SC, Legault G, Zagzag D, Burger PC, Allen JC, Eberhart CG, Bar EE: BRAF alterations in primary glial and glioneuronal neoplasms of the central nervous system with identification of 2 novel KIAA1549:BRAF fusion variants. J Neuropathol Exp Neurol 2012, 71:66 72

31. Vemurafenib FDA approval and full prescribing information [http://www. cancer.gov/cancertopics/druginfo/fda-vemurafenib]

32. West ES, Williams VL, Morelli JG: Vemurafenib-induced neutrophlic panniculitis in a child with a brainstem glioma. Pediatr Dermatol 2014. doi:10.1111/pde.12316

33. Rush S, Foreman N, Liu A: Brainstem ganglioglioma successfully treated with vemurafenib. J Clin Oncol 2013, 31:e159 e160.

34. Flaherty KT, Puzanov I, Kim KB, Ribas A, McArthur GA, Sosman JA, O Dwyer PJ, Lee RJ, Grippo JF, Nolop K, Chapman PB: Inhibition of mutated, activated BRAF in metastatic melanoma. N Engl J Med 2010, 363:809 819

35. Sosman JA, Kim KB, Schuchter L, Gonzalez R, Pavlick AC, Weber JS, McArthur GA, Hutson TE, Moschos SJ, Flaherty KT, Hersey P, Kefford R, Lawrence D, Puzanov I, Lewis KD, Amaravadi RK, Chmielowski B, Lawrence HJ, 
Shyr Y, Ye F, Li J, Nolop KB, Lee RJ, Joe AK, Ribas A: Survival in BRAF V600-mutant advanced melanoma treated with vemurafenib. New Engl J Med 2012, 366:707 714

36. Emery CM, Vijayendran KG, Zipser MC, Sawyer AM, Niu L, Kim JJ, Hatton C, Chopra R, Oberholzer PA, Karpova MB, MacConaill LE, Zhang J, Gray NS, Sellers WR, Dummer R, Garraway LA: MEK1 mutations confer resistance to MEK and B-RAF inhibition. Proc Natl Acad Sci 2009, 106:20411 20416.

37. Van Allen EM, Wagle N, Sucker A, Treacy DJ, Johannessen CM, Goetz EM, Place CS, Taylor-Weiner A, Whittaker S, Kryukov GV, Hodis E, Rosenberg M, McKenna A, Cibulskis K, Farlow D, Zimmer L, Hillen U, Gutzmer R, Goldinger SM, Ugurel S, Gogas HJ, Egberts F, Berking C, Trefzer U, Loquai C, Weide B, Hassel JC, Gabriel SB, Carter SL, Getz G, Garraway LA, Schadendorf D, Dermatologic Cooperative Oncology Group of Germany (DeCOG): The genetic landscape of clinical resistance to RAF inhibition in metastatic melanoma. Cancer Discov 2014, 4:94 109.

38. Poulikakos Pl, Persaud Y, Janakiraman M, Kong X, Ng C, Moriceau G, Shi H, Atefi M, Titz B, Gabay MT, Salton M, Dahlman KB, Tadi M, Wargo JA, Flaherty KT, Kelley MC, Misteli T, Chapman PB, Sosman JA, Graeber TG, Ribas A, Lo RS, Rosen N, Solit DB: RAF inhibitor resistance is mediated by dimerization of aberrantly spliced BRAF(V600E). Nature 2011, 480:387 390.

39. Villanueva J, Vultur A, Lee JT, Somasundaram R, Fukunaga-Kalabis M, Cipolla AK, Wubbenhorst B, Xu X, Gimotty PA, Kee D, Santiago-Walker AE, Letrero R, D Andrea K, Pushparajan A, Hayden JE, Brown KD, Laquerre S, McArthur GA, Sosman JA, Nathanson KL, Herlyn M: Acquired resistance to BRAF inhibitors mediated by a RAF kinase switch in melanoma can be overcome by cotargeting MEK and IGF-1R/PI3K. Cancer Cell 2010, 18:683 695 .

doi:10.1186/s12967-014-0356-1

Cite this article as: del Bufalo et al:: Response of recurrent BRAFV600E mutated ganglioglioma to Vemurafenib as single agent. Journal of

Translational Medicine 2014 12:356.

\section{Submit your next manuscript to BioMed Central and take full advantage of:}

$\bigotimes$ Convenient online submission

$\otimes$ Thorough peer review

$\nabla$ No space constraints or color $\nabla$ gure charges

$\nabla$ Immediate publication on acceptance

\Inclusion in PubMed, CAS, Scopus and Google Scholar

$\otimes$ Research which is freely available for redistribution 